\title{
A PRESENÇA E A PERMANÊNCIA DE PESSOAS TRANS EM AMBIENTE ESCOLAR NO BRASIL
}

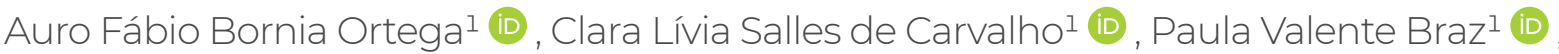 \\ Zuleika Zamoner ${ }^{1}$ (D) , Patrícia Ortiz Monteiro
}

\section{RESUMO}

Objetivou-se realizar pesquisa bibliográfica sobre pessoas trans em artigos científicos publicados nas bases de dados da Scientific Eletronic Library Online (SciELO) e da Coordenação de Aperfeiçoamento de Pessoal de Nível Superior (CAPES), entre ouras referencias, nos quais se discutem sua presença e sua permanência em ambiente escolar. Foram utilizadas diferentes combinações de descritores, devido à escassa produção acadêmica em relação aos temas da transgeneridade, da travestilidade e da transexualidade a partir de uma perspectiva não marginalizada, não patologizante e não cisgênera e/ou heterocentrada dessas identidades. As referências teóricas encontradas apontaram a cisgeneridade e o heterocentrismo como normas arbitrárias de existência e vivência que dificultam, quando não impedem, a presença e permanência de pessoas trans em ambientes escolares, descritos por elas como violentos. Os autores concluem que uma maneira de combater essa situação é o debate sobre gênero e identidades de gênero nas escolas.

Palavras-chave: Educação, Transgeneridade, Travestilidade, Transexualidade.

\section{THE PRESENCE AND PERMANENCE OF TRANS PERSONS IN A SCHOOL ENVIRONMENT IN BRAZIL}

\begin{abstract}
The objective was to carry out bibliographic research on transgender people in scientific articles published in the database of the Scientific Electronic Library Online (SciELO) and Coordenação de Aperfeiçoamento de Pessoal de Nível Superior (CAPES), in which their presence and permanence in the school environment are discussed. Different combinations of descriptors were used, due to the scarce academic production in relation to the themes of transgender, transvestite and transsexuality from a non-marginalized, non-pathologizing and non-cisgender and / or heterocentric perspective of these identities. The articles found pointed to cisgenerity and heterocentrism as arbitrary norms of existence and experience that hinder, when they do not prevent, the presence and permanence of trans people in school environments, described by them as violent. The authors conclude that one way to combat this situation is the debate about gender and gender identities in schools.
\end{abstract}

Keywords: Education. Transgender identity. Transvestility. Transsexuality.

\footnotetext{
1 Universidade de Taubaté (UNITAU)
}

Autor Correspondente: Patrícia Ortiz Monteiro

E-mail: patyortizmonteiro@terra.com.br

Recebido em 25 de Abril de 2021 | Aceito em 27 de Janeiro de 2022. 


\title{
LA PRESENCIA Y PERMANENCIA DE LAS PERSONAS TRANS EM EL ÁMBITO ESCOLAR EN BRASIL
}

\begin{abstract}
RESUMEN
El objetivo fue realizar una investigación bibliográfica sobre personas transgénero en artículos científicos publicados en las bases de datos de la Biblioteca Científica Electrónica en Línea (SciELO) e de la Coordenação de Aperfeiçoamento de Pessoal de Nível Superior (CAPES), entre otras referencias, en la que se discute su presencia y permanencia en el ámbito escolar. Se utilizaron diferentes combinaciones de descriptores, debido a la escasa producción académica en relación a los temas de transgénero, travesti y transexualidad desde una perspectiva no marginada, no patologizante y no cisgénero y / o heterocéntrica de estas identidades. Los artículos encontrados apuntaban a la cisgeneridad y al heterocentrismo como normas arbitrarias de existencia y experiencia que dificultan, cuando no impiden, la presencia y permanencia de personas trans en ambientes escolares, calificados por ellos como violentos. Los autores concluyen que una forma de combatir esta situación es el debate sobre género e identidades de género en las escuelas.
\end{abstract}

Palabras clave: Educación. Transgénero. Travesti. Transexualidad.

\section{INTRODUÇÃO}

Esse artigo tem como objetivo apresentar os resultados referentes à análise da produção acadêmica brasileira, entre outras referências de cunho cientifico, no que diz respeito ao tema da presença e da permanência de pessoas trans em ambiente escolar, bem como fomentar essa discussão relevante.

A expressão "pessoas trans" é utilizada como sinônimo de pessoas travestis e transexuais e as estatísticas demonstram que o Brasil é o país que mais mata pessoas transexuais no mundo, as quais têm expectativa média de vida de 35 anos. Ainda assim, não há dados oficiais sobre essa população no país (Pedra, 2020).

Segundo Torres e Prado (2014), existem várias articulações políticas para o enfrentamento da discriminação e da violência que tem ocorrido em âmbito nacional e internacional, que tem resultado em várias ações e posições políticas, e uma delas pode ser vista nos Princípios de Yogyakarta, documento preparado em novembro de 2006, na Indonésia, e encaminhado às Nações Unidas, cuja proposta define duas categorias de análise importantes nas pesquisas: orientação sexual e identidade de gênero.

O termo "orientação sexual" refere-se à capacidade de cada pessoa de ter uma profunda atração emocional, afetiva ou sexual por indivíduos de gênero diferente, do mesmo gênero ou de mais de um gênero, assim como ter relações íntimas e sexuais com essas pessoas, e o termo "identidade de gênero" é uma experiência interna e individual do gênero de cada pessoa, que pode ou não corresponder ao sexo atribuído no nascimento, incluindo o senso pessoal do corpo (que pode envolver, por livre escolha, modificação da aparência ou função corporal por meios médicos, cirúrgicos e outros) e outras expressões de gênero, inclusive vestimenta, modo de falar e maneirismos (Princípios de Yogyakarta, 2007).

Bento (2011) alega que a construção social da relação entre sexo, gênero e orientação social torna a categoria gênero polissêmica, não existindo um entendimento unânime sobre o que é gênero nos espaços acadêmicos ou nos ativismos políticos. A autora salienta, no entanto, que há uma disputa teórica sobre seu significado, que se materializa no Brasil, em políticas públicas que partem de uma concepção biológica sobre o gênero.

Segundo a Organização para a Cooperação e o Desenvolvimento Econômico (OCDE), pesquisas sobre atitudes em relação a homossexuais vêm sendo realizadas desde 1981 nos diferentes continentes. Já as pesquisas 
em relação a transexuais (pessoas trans) são mais recentes, com primeiros dados coletados em 2012. Apesar de existirem estudos sobre a evolução do número de pessoas que se identificam como lésbicas, gays e bissexuais (LGB), estimativas a respeito da população trans permanecem escassas. De acordo com a OCDE (2019), apenas três países coletam informações a respeito da identidade de gênero de sua população em pesquisas representativas: Estados Unidos da América (desde 2013), Chile (desde 2015) e Dinamarca (desde 2017).

Em termos comparativos, mesmo nos países que produzem dados estatísticos e demográficos sobre os perfis de gênero, a população composta por pessoas transexuais é pequena no universo total dessas estatísticas, o que leva a menor visibilidade das necessidades específicas do grupo. Segundo as pesquisas a participação das pessoas transexuais no total da população adulta representa 0,1\% no Chile e 0,3\% nos Estados Unidos da América, enquanto a população LGB chega a 1,9\% e 2,9\%, respectivamente (OCDE, 2019).

Assim, os dados coletados sobre orientação sexual oferecem apenas uma referência de como identidades e orientações sexuais que questionam a lógica cisgênera (cis) e heteronormativa de corpos e desejos são tratadas pela sociedade e nas escolas.

Note-se que, ao discorrer sobre a identidade de pessoas cis, utiliza-se apenas a palavra "identidade", pois a expressão "identidade de gênero" parece ser empregada para, e apenas para, pessoas não cis. Neste sentido, explica Simpson (2015, p. 11), os termos travestilidade e transexualidade foram criados pelo movimento social organizado para informar que ser travesti "[...] é uma questão de identidade e de modo de viver".

Como exemplo de pesquisa realizada sobre pessoas LGBTQIA+, vale destacar o estudo sobre homossexualidade realizado em parceria entre o Instituto Nacional de Estudos e Pesquisas Educacionais Anísio Teixeira (INEP) e a Fundação Instituto de Pesquisas Econômicas (FIPE), em 2008, sobre ações discriminatórias em âmbito escolar, que mostrou o grau de preconceito em relação à homossexualidade nas diversas populações que atuam nas escolas (INEP, 2009). O estudo quantitativo abrangeu 500 escolas públicas em todo o país, considerando Ensino Fundamental e Médio, escolas municipais e estaduais. Foram apresentadas algumas afirmações a diretores (501), professores (1.005), funcionários (1.004), alunos (15.087), pais e mães (1.002) com vínculo com essas instituições de ensino, e em seguida perguntou-se se eles concordavam com elas (INEP, 2009). Um recorte deste estudo pode ser observado na Tabela 1.

Tabela 1 - Pesquisa sobre ações discriminatórias no âmbito escolar

\begin{tabular}{cc}
\hline Afirmações dos atores & Porcentagem que concordam \\
\hline Pessoas homossexuais não são de confiança & $25 \%$ dos estudantes; \\
$17,5 \%$ de pais e mães; & $13,6 \%$ dos funcionários; \\
\hline Não se aproximar fisicamente de homossexuais & $4,2 \%$ entre professores; e \\
$4,1 \%$ entre diretores. \\
\hline $35 \%$ dos alunos; \\
$22,2 \%$ dos pais e mães; \\
$21,4 \%$ dos funcionários; \\
$13,3 \%$ de professores; e \\
$9,8 \%$ de diretores.
\end{tabular}




\begin{tabular}{|c|c|}
\hline \multirow{5}{*}{$\begin{array}{l}\text { Os alunos homossexuais são considerados anor- } \\
\text { mais }\end{array}$} & $21,1 \%$ dos colegas; \\
\hline & $14,4 \%$ dos pais e mães; \\
\hline & 12\% dos funcionários; \\
\hline & $3 \%$ dos professores; e \\
\hline & $2,2 \%$ dos diretores. \\
\hline \multirow{5}{*}{ São considerados doentes } & $28,2 \%$ dos pais e mães; \\
\hline & $23,2 \%$ dos colegas; \\
\hline & 23,4\% dos funcionários; \\
\hline & $29,3 \%$ dos professores; e \\
\hline & $26,2 \%$ dos diretores. \\
\hline \multirow{5}{*}{$\begin{array}{l}\text { Não aceitação da homossexualidade, da orienta- } \\
\text { ção sexual de uma pessoa que não a própria }\end{array}$} & $26,6 \%$ dos alunos; \\
\hline & 20,3\% dos pais e mães; \\
\hline & 20,5\% dos funcionários; \\
\hline & $10,6 \%$ dos professores; e \\
\hline & 10,9\% dos diretores. \\
\hline \multirow{5}{*}{$\begin{array}{l}\text { É considerável que alunos homossexuais sejam } \\
\text { segregados em escolas separadas }\end{array}$} & $17,6 \%$ de alunos; \\
\hline & 10,6\% dos pais e mães; \\
\hline & 6,9\% dos funcionários; \\
\hline & $1,7 \%$ dos professores; e \\
\hline & 1,8\% dos diretores. \\
\hline \multirow{5}{*}{$\begin{array}{l}\text { Os professores que não são gays são mais respei- } \\
\text { tados }\end{array}$} & 4,9\% de alunos; \\
\hline & $38,8 \%$ dos pais e mães; \\
\hline & 37,3\% dos funcionários; \\
\hline & $29,3 \%$ dos professores; e \\
\hline & $26,2 \%$ dos diretores. \\
\hline
\end{tabular}

Fonte: Adaptados pelos autores (INEP, 2009).

A pesquisa realizada pelo INEP (2009), traz um resultado desanimador no que diz respeito ao preconceito em relação a homossexualidade de forma geral, no ambiente escolar. Quanto a confiança, $25 \%$ dos estudantes e $17,5 \%$ de pais e mães, $13,6 \%$ dos funcionários, $4,2 \%$ dos professores e $4,1 \%$ dos diretores consideram que os homossexuais não são pessoas que mereçam confiança.

Quanto a aproximação física 35\% dos alunos, 22,2\% dos pais e mães, 21,4\% dos funcionários, 13,3\% de professores e 9,8\% de diretores não querem se aproximar fisicamente dos homossexuais.

Quanto a considerarem os homossexuais anormais ou doentes, é a opinião de mais de $20 \%$ dos estudantes, mais de $14 \%$ dos pais e mães, e mais de $12 \%$ de funcionários. Vale destacar que $29,3 \%$ dos professores e $26,2 \%$ dos professores consideram que os homossexuais são pessoas doentes. 
Outro exemplo de pesquisa, este específico sobre professoras transexuais e travestis no contexto escolar, foi realizada por Torres e Prado (2014). Os autores afirmam a partir do estudo que na escola e na sociedade em geral se reiteram as normas de gênero pelos discursos religiosos, médicos e morais. Portanto o lugar de professora torna-se, para muitos, uma dignidade imprópria às transexuais e travestis. Nesse sentido, para os autores, a busca das professoras entrevistadas pelo feminino idealizado pauta-se por processos extremamente complexos e tensos nas relações com a escola e fora dela.

Atitudes homofóbicas profundamente enraizadas, muitas vezes combinadas com uma falta de proteção jurídica contra a discriminação em razão de orientação sexual e identidade de gênero, expõem muitas pessoas, de todas as idades e em todas as regiões do mundo, a violações evidentes de seus direitos humanos. Elas são discriminadas no mercado de trabalho, nas escolas e nos hospitais, e maltratadas e rejeitadas por suas próprias famílias. Nas ruas das cidades ao redor do mundo, são as "escolhidas" para o ataque físico - espancadas, agredidas sexualmente, torturadas e mortas (UNHCHR, 2013).

De acordo com o Grupo Gay da Bahia, só em 2016, 343 pessoas lésbicas, gays, bissexuais, travestis e transexuais foram assassinadas no Brasil tendo o crime motivado pela orientação sexual. É como se um LGBTQIA+ fosse morto a cada 25 horas no país (ABGLT, 2010).

Diante deste cenário, essa discussão se torna relevante e particularmente importante, uma vez que o Brasil é uma dos que mais mata, violenta e discrimina pessoas LGBTQIA+.

\section{CISGENERIDADE E HETEROCENTRISMO: A PERMANÊNCIA DA CONSTRUÇÃO SOCIAL DA RELAÇÃO ENTRE SEXO E GÊNERO NO AMBIENTE ESCOLAR}

Segundo Laqueur (2001) a construção social de um discurso sobre o gênero se dá a partir da construção social de um discurso sobre o sexo. Esta, por sua vez, ocorre a partir de um discurso científico e biológico sobre a anatomia de apenas duas possibilidades de corpos. O autor cita que no entendimento, de forma geral, há uma possibilidade de corpo que é o daquele que porta um pênis, chamado de masculino, um corpo de homem, e a outra possibilidade de corpo é o daquele que porta uma vagina e duas mamas proeminentes, chamado de feminino, um corpo de mulher, eliminando-se, assim, qualquer outra possibilidade de configuração anatômica.

Para esse autor, o sexo é situacional e só pode ser analisado a partir da luta sobre gênero e poder. Tudo o que é arbitrariamente nomeado de biológico versa sobre diferenças ou igualdades anatômicas, descritas segundo uma ideologia e ignorando-se, quando necessário, a exatidão das observações. Considera-se, também, que o corpo do homem é superior ao da mulher (Laqueur, 2011).

Existiu um trabalho coletivo para socializar o biológico e biologizar o social, produzindo nos corpos e nas mentes das pessoas uma naturalização dos gêneros como sexuados. Esses discursos não produzem apenas corpos-homens e corpos-mulheres; exigem que esses corpos e seus gêneros coerentes orientem seus desejos aos que consideram seus opostos complementares. Criam uma relação entre sexo, gênero e desejo (Butler, 2020).

A cisgeneridade e o heterocentrismo partem dessa lógica de discurso biológico e são três os elementos da cisgeneridade: pré-discursividade, binariedade e permanência.

Segundo a cisgeneridade estabelece, assim, o corpo cis como referência de verdade, normalidade e saúde, e consequentemente, patologiza a transgeneridade.

As identidades sociais, como a de gênero, a sexual, a de raça e a de classe são definidas pela cultura e pela história. A pré-discursividade é o mito coletivo de que característica naturais definem as identidades de gênero (Vergueiro, 2016). 
A binariedade refere-se ao discurso sobre a existência de corpos-homens e corpos-mulheres, exigindo-lhes que sejam heterossexuais. Já a permanência, um encontro entre a pré-discursividade e a binariedade, pressupõe uma coerência entre corpo e gênero; qualquer desvio de um suposto destino natural e biológico é considerado uma ameaça e um perigo à natureza, aos corpos e às identidades de gênero.

Para Bento (2008, p. 169), é preciso que se entenda que a diferença é anterior e que constitui a suposta igualdade, uma vez que "[...] a humanidade se organiza e se estrutura na e pela diferença". A partir dessa compreensão, é possível inverter a lógica, não identificando o estranho como o diferente, mas pensar que estranho é ser igual. A autora considera um equívoco falar-se em "diferença" e "diversidade" no ambiente escolar, porque se pressupõe a existência de um "lado da igualdade" onde estariam as pessoas que "agem naturalmente de acordo com valores hegemônicos" (Bento, 2011, p. 158), em oposição às outras pessoas, que agiriam diferente.

Diante disso, passemos a analisar a escola, tal qual a conhecemos hoje. A escola herdada da sociedade ocidental moderna, de acordo com Louro (1997), foi inicialmente idealizada para atender a apenas algumas pessoas. No entanto, começou a ser requisitada por pessoas que não estavam contempladas em seu projeto original, o que a obrigou a se diversificar. Em contrapartida, instituiu instrumentos que garantissem a produção de diferenças entre os sujeitos por meio de mecanismos de classificação, ordenamento e hierarquização. Nesse contexto, a escola "[...] imediatamente separou os meninos das meninas" (Louro, 1997, p. 57). Para a autora, a escola delimita espaços, estabelece símbolos e códigos, estabelece modelos a serem seguidos, impõe o que cada um pode ou não pode fazer, e separa e institui o lugar das meninas e dos meninos.

Segundo Louro (1997, p. 60), “[...] a escola é parte importante de um processo social e cultural de práticas instituídas, aprendidas e interiorizadas e arbitrariamente tomadas como "naturais".

Para Pedra (2006), o processo de socialização tem início na família, com o nascimento, e a escola é um dos espaços de convívio social em que esse processo de socialização continua. Não por acaso, esses espaços propiciam a manutenção da cisgeneridade e do heterocentrismo simultaneamente, com momentos de discriminação, obviamente também a pessoas trans.

Bento (2008) explica que as violências praticadas contra pessoas trans são múltiplas, e que a patologização das identidades talvez seja a mais cruel delas. Para a autora, isso ocorre porque a possibilidade de se reivindicar direitos humanos está restrita a um grupo muito reduzido de sujeitos: homens masculinos, brancos, heterossexuais e membros de uma elite econômica, política e/ou intelectual. Em outras palavras, as normas de gênero apenas reconhecem como sujeitos de direitos humanos aqueles que se encontram em corpos sexuados adequados ao seu gênero. A autora chama atenção para o fato de os casos em que as crianças deixam a escola em razão de um ambiente escolar hostil serem chamados de "evasão", pois, na realidade, essas crianças são vítimas de violências que as fazem abandonar o ambiente escolar a fim de evitá-las. Existe diferença entre "evasão" e "expulsão", e apenas quando se sabe com precisão as causas que levam crianças e adolescentes a não frequentarem o ambiente escolar é que se pode enfrentá-las com eficácia, a exemplo da intolerância em relação a crianças e adolescentes trans (Bento, 2008).

\section{A TÍMIDA PRODUÇÃO ACADÊMICA BRASILEIRA SOBRE PESSOAS TRANS NO AMBIENTE ESCOLAR}

Para fins desse artigo foi realizada pesquisa bibliográfica em fontes primárias e secundárias, a partir da utilização de referências teóricas como livros, artigos científicos, dissertações e teses. Os dados foram obtidos a partir de obras escritas e impressas em editoras, bem como por meio de pesquisa eletrônica, utilizando sites de busca de artigos, dissertações e teses. 
O levantamento das produções acadêmicas brasileiras é um bom indicativo sobre o interesse e o investimento intelectual na temática tratada. Assim, a pesquisa envolveu levantamento bibliográfico no banco de dados da SciELO e da CAPES, utilizando como um dos filtros, as pesquisas mais recentes, estabelecendo o período de 10 anos (2011-2021).

A maior parte dos artigos, dissertações e teses sobre pessoas trans são da área da saúde e/ou tratam da violência contra os transexuais. Foram utilizados os descritores: "pessoas trans" e "transexuais" de forma separada e, esses descritores também foram combinados, separadamente (em dupla) com outros: "escola"; "ambiente escolar" e "contexto escolar".

Os descritores foram utilizados nas seguintes combinações: "pessoa trans" e "escola", "pessoa trans" e "ambiente escolar", "pessoa trans" e contexto escolar", "transexuais" e "escola", "transexuais" e "ambiente escolar" e "transexuais" e contexto escolar".

No banco de dados SCIELO quando utilizamos os descritores "pessoa trans" ou "transsexuais" de forma isolada apareceram setenta e um trabalhos.

Quando combinamos os descritores em duplas, nenhum artigo foi encontrado quando as combinações dos descritores foram "transexuais" com "ambiente escolar" ou "transsexuais" com "contexto escolar".

A partir do descritor "pessoas trans" combinado com o descritor "escola", apenas um artigo foi encontrado. Neste, Molina (2020) apresenta uma escola voltada especialmente para a população trans, na cidade de Buenos Aires, na Argentina. Sua pesquisa teve como foco especificamente a compreensão dos processos de transições corporais de estudantes que frequentavam aquela escola, denominada Bachillerato Popular Trans Mocha Celis.

A partir da combinação do descritor "transexuais" e do descritor "escola", foram encontrados nove artigos. Desses, sete foram desconsiderados, por se repetirem quando comparados a combinação de outros descritores pesquisados. Dois artigos tinham por objetivo compreender e descrever a percepção de mulheres transexuais sobre si mesmas: um deles, em relação à representação social de seus corpos, e o outro, em relação ao processo transexualizador. Por esse motivo, foram desconsiderados.

Dos onze artigos encontrados, resultantes das combinações de descritores "pessoas trans" com "ambiente escolar" e "pessoas trans" com "contexto escolar", dois deles versavam sobre pessoas trans, mas em contexto diverso do ambiente escolar, portanto foram desconsiderados, restando nove artigos.

Destes nove, cinco não apresentavam pesquisa específica sobre o tema da presença e permanência de pessoas trans em ambiente escolar, embora mencionassem o ambiente escolar como um dos espaços de violências praticadas contra pessoas trans: Torres et al. (2020), Moreira et al. (2018), Silva et al. (2016), Souza et al. (2015) e Sousa et al. (2013).

Torres et al. (2020) discorrem sobre a violência ética e a luta por reconhecimento das sexualidades no contexto escolar. Os autores salientam o silenciamento de questões sobre travestilidade e transexualidade nos grupos focais, o que indicou, segundo eles, que o epistemicídio opera de maneira mais violenta sobre esses corpos.

Moreira et al. (2018) analisaram a concepção de gênero presente na Resolução no 002 do Conselho Municipal de Educação de Belo Horizonte, que legitima o uso do nome social por estudantes travestis e transexuais nos registros internos das escolas municipais.

Silva et al. (2016) apenas mencionam o ambiente escolar como um dos espaços em que pessoas travestis e transexuais sofrem algum tipo de violência. 
Souza et al. (2015), investigaram violências sofridas por travestis na cidade de Santa Maria, no Estado do Rio Grande do Sul, e indicam o âmbito escolar como um dos espaços de reprodução de uma ordem social heteronormativa onde violências são praticadas contra travestis.

Sousa et al. (2013), que investigaram homofobia e vulnerabilidade ao HIV/Aids de pessoas travestis na Região Metropolitana do Recife, também indicam o ambiente escolar como um dos espaços em que travestis são expostas à homofobia.

Assim, restaram quatro artigos científicos que se dedicam integralmente a discutir a presença e a permanência de pessoas trans em ambiente escolar. Nos artigos publicados por Sales et al. (2017), Santos (2015), Dinis e Pamplona (2014) e Torres e Prado (2014) percebeu-se dedicação integral ao tema da presença e permanência de pessoas trans no ambiente escolar, e foram usados nessa discussão.

No banco de dados da CAPES quando utilizados os descritores separadamente "pessoa trans" ou transexuais" foram encontrados trinta e cinco documentos, e quando combinamos os descritores em dupla, foram obtidas onze pesquisas, que abordam a presença e permanência dos transexuais no ambiente escolar.

\section{A AUSÊNCIA DE DADOS FORMAIS SOBRE PESSOAS TRANS EM AMBIENTE ESCOLAR $N O B R A S I L$}

O artigo 205 da Constituição Federal (BRASIL, 1988) define a educação como um direito de todos e dever do Estado e da família, devendo ser promovida e incentivada com a colaboração da sociedade. Nessa perspectiva, visa ao pleno desenvolvimento da pessoa, seu preparo para o exercício da cidadania e sua qualificação para o mundo do trabalho.

O inciso I do art. 206 da mesma Constituição garante que o ensino será ministrado a partir do princípio de igualdade de acesso e permanência na escola (BRASIL, 1988). No entanto, não é o que acontece na prática, como informam as poucas pesquisas realizadas na última década no Brasil sobre o tema da presença e permanência de pessoas trans em ambiente escolar (Pedra, 2020). Ainda que pessoas trans consigam acessar as escolas, permanecer nelas é um desafio que lhes é imposto a partir do momento em que expressam sua identidade (de gênero).

Tanto a educação formal quanto a informal ensinam cidadania. Por isso, movimentos sociais e Organizações Não Governamentais (ONGs) buscam diálogos com o Ministério da Educação (MEC) para que currículos escolares abordem questões sociais propiciando ambientes formais de educação mais inclusivos (Pedra, 2020).

O autor chama atenção para uma movimentação conservadora que avança sobre o Brasil e sobre o currículo escolar. Grande parte do poder Legislativo do país mobiliza-se com o objetivo de impedir a discussão de gênero nas escolas. Em 2017, o Conselho Nacional de Educação, sob orientação do MEC, retirou todas as referências relacionadas a gênero e orientação sexual do texto da Base Nacional Comum Curricular -BNCC (Brasil, ano da publicação).

A ausência de dados oficiais sobre a população trans no Brasil reflete esse conservadorismo apontado por Pedra (2020). O Instituto Brasileiro de Geografia e Estatística (IBGE), por exemplo, não dispõe de dados específicos em relação à população trans ou à identidade de gênero. A maior parte das pesquisas realizadas pela sociedade civil organizada traz pouca especificidade sobre o público trans. 
Segundo Carrara, Sérgio et al. (2006), a pesquisa realizada na 9ạ Parada do Orgulho GLBT ${ }^{1}$ (Gays, Lésbicas, Bissexuais, Travestis e Transexuais) em São Paulo, em 2005, traz dados significativos sobre a incidência de situações constrangedoras no ambiente escolar, como pode ser observado na Tabela 2.

Tabela 2 - Incidência de situações constrangedoras a que são submetidos

\begin{tabular}{|c|c|}
\hline Afirmação e questionamentos dos atores & Porcentagem que concordam \\
\hline $\begin{array}{c}\text { Já foram marginalizados ou excluídos por colegas } \\
\text { ou professores na escola ou universidade }\end{array}$ & $\begin{array}{c}\text { bissexuais - } 44,7 \% \text {; } \\
\text { homossexuais - } 37,6 \% \text {; } \\
\text { pessoas trans - } 30,4 \% \text {; } \\
\text { mulheres bissexuais - } 26,1 \% \text {; } \\
\text { entre mulheres homossexuais - } 22,7 \% \text {. }\end{array}$ \\
\hline $\begin{array}{l}\text { Sentiram-se inseguros em instituição educacio- } \\
\text { nal no último ano em razão de sua orientação } \\
\text { sexual }\end{array}$ & $\begin{array}{l}42,8 \% \text { sentiram-se inseguros em razão da manei- } \\
\text { ra como expressavam o gênero. }\end{array}$ \\
\hline $\begin{array}{l}\text { Quais são os locais e momentos de maior cons- } \\
\text { trangimento ou insegurança para os estudantes? }\end{array}$ & $\begin{array}{l}\text { banheiros }(38,4 \%) ; \\
\text { vestiários }(30,6 \%) ; \\
\text { aulas de Educação Física }(22,1 \%) \text {. }\end{array}$ \\
\hline $\begin{array}{l}\text { Constrangimento ou insegurança são motivos } \\
\text { para faltar as aulas }\end{array}$ & $31,7 \%$. \\
\hline $\begin{array}{c}\text { Foram expostos a comentários preconceituo- } \\
\text { sos em relação à identidade e/ou expressão de } \\
\text { gênero }\end{array}$ & $47,5 \%$ dos estudantes. \\
\hline $\begin{array}{l}\text { Por quem os comentários preconceituosos foram } \\
\text { proferidos? }\end{array}$ & $\begin{array}{c}21,7 \% \text { por pares; } \\
69,1 \% \text { - por professores e/ou outros funcionários } \\
\text { da instituição educacional. }\end{array}$ \\
\hline $\begin{array}{l}\text { São frequentes os comentários preconceituosos } \\
\text { sobre pessoas trans }\end{array}$ & $54,7 \%$ dos estudantes; \\
\hline $\begin{array}{l}\text { Já foram agredidos verbalmente no último ano, } \\
\text { no âmbito da instituição educacional, em razão de } \\
\text { sua orientação sexual }\end{array}$ & $\begin{array}{l}72,6 \% \text { dos estudantes LGBT (agressões acontece- } \\
\text { ram com frequência para } 22,8 \% \text { deles). }\end{array}$ \\
\hline $\begin{array}{l}\text { Já foram agredidos fisicamente, tanto por orien- } \\
\text { tação, quanto por expressão de gênero }\end{array}$ & $14,7 \%$ dos estudantes. \\
\hline
\end{tabular}

Fonte: Adaptados pelos autores (Carrara, et al. 2006).

Os resultados da pesquisa, no entanto, não descrevem a natureza das violências impostas contra os entrevistados e indicam que a discriminação no ambiente escolar se dá por dinâmicas sutis. Para os pesquisadores, a incidência desse tipo de discriminação aparece mais elevada entre bissexuais, talvez porque $42,1 \%$ deles frequente escolas e universidades (Carrara et al., 2005, p. 42).

1 A 1ạ Conferência Nacional de Gays, Lésbicas, Bissexuais, Travestis e Transexuais decidiu, em 2008, padronizar a nomenclatura usada pelos movimentos sociais e pelo governo, junto com o padrão usado no resto do mundo; em lugar de GLBT, a sigla passa a ser LGBT: Lésbicas, Gays, Bissexuais, Travestis e Transexuais. Mais recentemente passou-se a utilizar LGBTQIA+. As letras Q, I e A e o sinal + foram integradas na sigla. O Q é de 'Queer' e são aquelas pessoas que transitam entre as noções de gênero, o I é de 'Intersexo' e são as pessoas que estão entre o feminino e o masculino e não se enquadram na norma binária, o A é de 'Assexual' e se refere as pessoas que não sentem atração sexual ou que entendem que isso não é prioridade, e o + é utilizado para incluir outros grupos e variações de sexualidade e gênero. 
A pesquisa observou ainda que o constrangimento e a insegurança afetam o desempenho escolar desses estudantes e, por vezes, levam-nos a abandonar o estudo.

Andrade (2012), em sua tese "Travestis na escola: Assujeitamento e resistência à ordem normativa", retrata as travestis no espaço escolar a partir de suas próprias narrativas sobre suas sociabilidades, resistências e assujeitamentos à ordem normativa, trazendo resultados bem interessantes. A autora indaga sobre as possibilidades de resistência diante de interdições e práticas reguladoras do sexo existentes no âmbito escolar. Enfatiza, em seu estudo, a importância de retratar as expressões culturais juvenis de travestis que não tenham relação com a prostituição, considerando que textos acadêmicos, tanto no Brasil quanto internacionalmente, têm explorado esse campo nos últimos 20 anos.

A autora ao apresentar sua motivação pessoal para pesquisar sobre travestis em ambiente escolar, relata que desde criança sofria com a imposição e com a segregação de comportamentos determinados para alunas e alunos, e que era violentamente castigada, tanto física quanto verbalmente, quando buscava qualquer tentativa de cruzamento da linha de fronteira que separava os gêneros masculino do feminino. Como professora, em sua vida adulta, ratifica que, "[...] para chegar até aqui foi necessário penetrar nas regras do jogo disciplinar e normativo da escola e da sociedade" e criar estratégias que a tirassem de uma situação de marginalidade perpétua, "[...] mesmo que muito bem vigiada e preparada para receber punição, pois aprendeu desde muito cedo, que o menor dos seus erros [...] poderia ser desculpa para uma retaliação" (Andrade, 2012, p. 20).

Segundo a autora, a dificuldade dos diretores das escolas em identificar e diferenciar alunas travestis de alunos gays evidencia falta de informação e dificuldade para lidar com o assunto, e levanta a hipótese de que, ao serem reconhecidos como sinônimos, entra em cena o determinismo biológico, que explica o tratamento masculino imposto às travestis na escola. Ainda que pessoas trans tenham acesso ao ensino e consigam concluir os ciclos de Educação Básica, o Ensino Superior não é uma realidade para todas elas (Andrade, 2012).

\section{A PRESENÇA E PERMANÊNCIA DE PESSOAS TRANS EM AMBIENTE ESCOLAR NO BRASIL}

Vigano e Laffin (2019), citam que a escola se fundamentou em bases heterossexuais, brancas, cristãs e masculinas, o que fez com que as pessoas que fujam a essa regra sejam vistas como estranhas. "A função social da escola tem como base a socialização aliada ao saber,contribuindo na construção de um país com igualdade, humanidade e justiça social" (Vigano e Laffin, 2019), e as questões de gênero e sexualidade devem fazer parte do debate de sala de aula, até mesmo porque há uma constante invisibilidade dessas questões no que tange a homossexualidade e a transgeneridade. A ocultação dessas discussões no currículo escolar fortalece o preconceito e a discriminação.

Segundo os mesmos autores, o currículo educacional ainda se mostra "tímido" em relação ao debate de gênero e sexualidade na escola, mas pode-se dizer que houve avanços. O Ministério da Educação (MEC) buscou a implementação de políticas públicas em educação com a finalidade de valorizar a diversidade étnico-racial e combater o racismo, promover a equidade de gênero e também, combater todas as formas de discriminação social, entre os anos de 2000 a 2006. Entretanto recentemente a nova Base Curricular Comum (BNCC) retirou a discussão de gênero, destacando as temáticas em torno da diversidade e da sexualidade, voltadas a saúde e a reprodução nos anos finais, e isso faz com que haja uma redução da complexidade dessas categorias - gênero e sexualidade, deixando todo o conjunto de discussão no mesmo patamar, desconsiderando as violências cotidianamente sofridas por pessoas com diferentes orientações sexuais ou identidades de gênero (Vigano e Laffin, 2019). 
Os autores Sales, Souza e Peres (2017) problematizam os processos de subjetivação que guardam relação com as travestilidades e os atravessamentos por novas configurações de expressões de gênero, sexualidades e corporalidades, na contemporaneidade. Para tanto, elegem a escola como cenário. Assim, consideram importante informar ao leitor que se apoiam em teóricos que não produzem nem reproduzem discursos que marginalizam vidas, mas retratam vidas com menos sofrimento e mais êxitos. Buscam, então, responder como as travestilidades podem ser pensadas desde a escola. Corroborando Louro (2018), Sales, Ferreira e Sá (2017) consideram a escola um espaço institucional tradicional e instrumento da modernidade para a produção de corpos normatizados. Esses corpos são disciplinados, controlados e administrados por forças e relações de poder.

Para Sales, Souza e Peres (2017), a escola produz a normalidade desejada por uma sociedade que é capitalista, burguesa, heteronormativa e patriarcal e considera a existência das travestilidade inviável, causadora de caos e desordem. Essa visão confronta com as pessoas travestis em idade escolar, uma vez que

[...] estão em meio a um processo de produção de outro gênero [...] as travestilidades se conjugam com a juventude, no sentido de que vão se constituindo em tempos que não são cronológicos, segmentados, universalizantes e progressivos (Sales et al., 2017, p. 73).

Os autores (2017) concluem que há necessidade de ideias e produções que potencializem as travestilidades, retratando-as como positivas, para que possam ser assumidas, contempladas e respeitadas. É preciso romper com a hierarquia de conceitos binários que estigmatizam feminilidades e masculinidades. Os contextos acadêmicos devem "[...] se comprometer eticamente e politicamente com produções psicossociais, educacionais e científicas", para que assim, se contemplem os direitos básicos de todas as pessoas (Sales et al. 2017, p. 80).

Santos (2015) propõe-se a um diálogo com os conceitos de Foucault para pensar a transexualidade nas escolas. Reflete sobre a invenção do dispositivo da transexualidade e os agenciamentos biopolíticos da instituição escolar sobre os corpos e subjetividades de pessoas trans e problematiza o direito ao uso do nome social nas escolas como uma conquista e, ao mesmo tempo, como uma estratégia de controle do governo sobre essas pessoas. A autora informa que dois municípios (um em Belo Horizonte e um em Fortaleza), os estados do Pará, Maranhão, Paraná, Alagoas, Rio Grande do Sul, Mato Grosso, Santa Catarina, Goiás, São Paulo, Bahia, Tocantins e o Distrito Federal têm alguma regulamentação sobre o direito ao uso do nome social nas escolas por travestis e transexuais. Isso porque não há uma legislação nacional que assim o faça.

Em seu estudo, Santos (2015) cita a Resolução n. 12/2015, do Conselho Nacional de Combate à Discriminação e Promoção de Direitos de Lésbicas, Gays, Bissexuais, Travestis e Transexuais (CNCD LGBT), órgão vinculado à Secretaria de Direitos Humanos (SDH), da Presidência da República, naquele ano. O documento apresenta posicionamentos e orientações claras sobre o uso do banheiro escolar em consonância com a identidade de gênero, o modo de uso do nome social nas escolas e o reconhecimento da identidade de gênero de menores de 18 anos. De acordo com a autora, assim que uma matrícula é solicitada por um ou uma estudante transexual ou travestis, a escola, apesar de acatá-la, coloca-se em estado de alerta e vigilância, alvoraçando-se "[...] as rotinas e dinâmicas, e a escola se coloca a pensar e a criar outras estratégias para lidar com situação de forma que o controle e a ordem sejam preservados, a qualquer custo, em um exercício biopolítico" (Santos, 2015, p. 634).

Isso acontece, segundo Santos (2015, p. 639), porque as escolas "[...] não suportam trabalhar com transexuais, pois empreendem toda uma maquinaria com vistas a estabelecer e reiterar a norma heterossexual". A escola não teria encontrado, até o momento, segundo a autora (2015), meios de capturar corpos trans e torná-los viáveis para o consumo e a produção. O corpo trans deveria deflagrar um processo de reorganização da instituição; no entanto, não o faz, o que ocasiona os processos de exclusão. Conclui expondo o desafio que se coloca para a educação e para as escolas: de "[...] se pensar a partir da diferença e da multiplicidade como uma expressão da alteridade" (Santos, 2015, p. 649). 
Dinis e Pamplona (2014) analisaram os discursos do vídeo educativo "Encontrando Bianca", sobre o corpo travesti. O vídeo era parte integrante do material educativo "Kit anti-homofobia", elaborado pela organização não governamental Comunicação em Sexualidade (ECOS), que foi submetido à avaliação do Ministério da Educação no ano de 2011. O Governo Federal, à época, estudava diferentes propostas para enfrentar e combater a homofobia em instituições escolares brasileiras; no entanto, em decorrência da polêmica fomentada pelas mídias brasileiras em torno do vídeo, que foi divulgado extraoficialmente, o material foi suspenso, por veto da Presidenta Dilma Rousseff (Dinis \& Pamplona, 2014).

Segundo os autores, o kit era um dos produtos do projeto "Escola sem Homofobia", que visava dar continuidade às políticas públicas contra a homofobia que tiveram início com o lançamento do programa federal "Brasil sem Homofobia", durante o governo Lula no ano de 2004. Um dos objetivos do programa era promover a produção de estudos e pesquisas que pudessem gerar conhecimentos para o combate à violência e à discriminação em razão de orientação sexual. Embora sem a consecução das metas do programa, todas as ações para sua efetivação foram concretizadas. O Ministério da Educação e a SDH estiveram em constante diálogo com a Global Alliance for LGBT Education (GALE), com a Comunicação em Sexualidade (ECOS), com a Pathfinder do Brasil e com a Associação Brasileira de Lésbicas, Gays, Bissexuais, Travestis e Transexuais (ABGLT), para concretização dessas ações (Dinis \& Pamplona, 2014).

Para os autores, o vídeo mostra paradoxos. Ao mesmo tempo em que retrata uma travesti beneficiada pela revolução tecnológica dos séculos XX e XXI, convida-a a se esconder, devido a ameaça de protestos, violências e punições. De acordo com Dinis e Pamplona (2014), o paradoxo é ampliado quando se diz que Bianca tem seu corpo moldado, como se essas tecnologias - médicas, farmacêuticas e estéticas - fossem indispensáveis para a transformação em um novo corpo. Além disso, não é possível se falar de um corpo único das travestis. Nesse caso, o vídeo acaba por constituir um discurso que condiciona o corpo das travestis a um corpo que se assemelharia ao corpo feminino ideal, que não incomoda, que não perturba tanto, que não é nem vulgar nem chamativo ou agressivo, um corpo de unhas vermelhas, porém curtas (Dinis \& Pamplona, 2014).

Bianca é retratada como uma moça boa que se adequa aos discursos hegemônicos do que se espera de uma mulher. Nas palavras dos autores, ela é "[...] apresentada de forma convergente com os valores e os padrões estabelecidos por uma cultura ocidental, branca, burguesa e heterossexista". Até mesmo suas roupas estão enquadradas em um discurso sexista, - são discretas e em tons neutros. O cachecol "[...] impossibilita identificar a presença de seios, tão desejados pelas travestis" (Dinis \& Pamplona, 2014, p. 230).

Para os autores, o vídeo pode sugerir um modelo de corpo que poderia ser tolerado no espaço escolar e incorporado por travestis que os frequentem. Chamam a atenção para a necessidade de se pensar se a própria produção do vídeo não esbarra nas normatizações, desviando-se dos objetivos do projeto "Escola sem Homofobia".

Torres \& Prado (2014) fazem um recorte específico sobre algumas experiências de professoras autodefinidas como transexuais femininas e travestis. A pesquisa buscou responder à pergunta: Como transexuais femininas ou travestis se mantêm na função de professoras, em um contexto marcado pela homofobia? Os pesquisadores realizaram entrevistas individuais com sete professoras, e observações em espaços de encontros coletivos de pessoas LGBT e em espaços de encontros coletivos específicos de travestis e transexuais. Constataram que dois documentos se mostraram de frequente importância nos debates desses coletivos, pois traziam demandas específicas de travestis e transexuais, como o respeito ao uso do nome social, o acesso a direitos básicos, viabilização de processos médicos para utilização de hormônios pelo Sistema Único de Saúde (SUS), entre outros. Os documentos sobre políticas de direitos humanos são "Princípios de Yogyakarta” (2007) e "Plano Nacional de Promoção da Cidadania e Direitos Humanos LGBT” (2009). 
Para Torres \& Prado (2014), a presença de professoras trans no contexto escolar favorece uma alteração na balança de poder que a heteronormatividade delimita no campo da educação. A fim de demonstrar tal argumento, os pesquisadores apresentam a fala de uma das professoras entrevistadas que relata que, em um primeiro momento, existe uma repulsa à sua identidade de gênero. No entanto, segundo ela, o convívio permite que as pessoas a conheçam e construam um vínculo de afeto com ela. Acredita que sempre encontrará essa resistência, mas observa que a maioria das pessoas é capaz de rever suas posturas e mudar seu posicionamento.

Uma das professoras entrevistadas por Torres e Prado (2014) relatou nunca ter sofrido qualquer tipo de violência em ambiente escolar, o que lhe serviu de motivação para ocupar espaços sociais e realizar seu desejo de infância: ser professora. Os autores trazem a informação de que essas professoras estão em constante negociação, no ambiente escolar, sobre direitos humanos, identidades de gênero e sobre a maneira de exercê-los, uma vez que "[...] se assumir publicamente como transexual ou travesti, realizar mudanças corporais e no vestuário de acordo com sua identidade de gênero é colocar-se num lugar ameaçado". Concomitantemente, trata-se de "[...] demandar reconhecimento pela sua forma de vida, exigir direitos como os demais sujeitos" (Torres \& Prado, 2014, p. 212).

Esse estudo revela, não apenas um assujeitamento à cisheteronormatividade, mas também à importância de suas presenças no ambiente escolar, para mudança das dinâmicas de poder. Apesar dessas aparentes conquistas, os autores alertam que as professoras entrevistadas ainda "[...] são definidas como alguém perigoso, a ser barrado" (TORRES; PRADO, 2014, p. 215).

\section{CONSIDERAÇÕES FINAIS}

O resultado do levantamento de publicações científicas sobre pessoas trans, travestis e transexuais demonstra concentração em temas como violência, processo transexualizador, prostituição e infecções sexualmente transmissíveis e HIV/Aids. Nos últimos dez anos, o número de quatro artigos sobre a presença e permanência de pessoas trans em ambiente escolar, demonstra claramente a carência de estudos nessa área.

As pesquisas encontradas sobre o tema da presença e permanência de pessoas trans em ambiente escolar apontam para um ambiente escolar conservador e regido pela lógica de um pensamento cisheteronormativo, que pressupõe o binarismo de gênero de base biológica, pelo qual se nasce homem ou mulher: a partir de uma determinada configuração de corpo, mais especificamente, pela presença de pênis ou vagina, respectivamente. A partir de então, espera-se que esses corpos performem gênero e orientação sexual, arbitrariamente, coerentes.

A ausência de dados e a quantidade ínfima de pesquisas sobre o tema traz um alerta para a urgência de se discutir mais amplamente com a sociedade, especialmente em ambiente escolar, que é um dos espaços de socialização e construção de cidadania de crianças e adolescentes que contribuem e contribuirão para um coletivo mais humano, justo e respeitoso, excluindo-se, dessa forma, o preconceito.

\section{REFERÊNCIAS}

ABGLT. Pesquisa nacional sobre o ambiente educacional no brasil 2016. Curitiba: Universidade Federal do Paraná, 2016. Disponível em: https://static.congressoemfoco.uol.com.br/2016/08/IAE-Brasil-Web-3-1.pdf. Acesso em: 8 dez. 2020.

ABGLT. Manual de Comunicação LGBT. Curitiba: ABGLT, 2010. https://unaids.org.br/wp-content/uploads/2015/09/Manual-de-Comunica\%C3\%A7\%C3\%A3o-LGBT.pdf. Acesso em: 4 set. 2021. 
ALMEIDA, Cecília Barreto de; VASCONCELLOS, Victor Augusto. Transexuais: transpondo barreiras no mercado de trabalho em São Paulo? Rev. Direito GV, São Paulo, v. 14, n. 2, p. 303-333, ago. 2018. Disponível em: http://www.scielo.br/scielo.php?script=sci_arttext\&pid=S1808-24322018000200303\&lng=en\&nrm=iso. Acesso em 5 nov. 2020.

ANDRADE, Luma Nogueira de. Travestis na escola: assujeitamento e resistência à ordem normativa. 2012. (Tese) Doutorado - Universidade Federal do Ceará. Disponível em: http://www.repositorio.ufc.br/handle/riufc/7600. Acesso em 5 nov. 2020.

BENTO, B. A. de M. O que é transexualidade? São Paulo: Brasiliense, 2008 (Primeiros Passos, n. 328).

BENTO, B. Na escola se aprende que a diferença faz a diferença. Revista de Estudos Feministas - REF, Florianópolis, v. 2, n. 19, p.548-559. Maio-agosto/2011. Disponível em: https://www.scielo.br/j/ref/a/DMNhmpzNbKWgH8zbgQhLQks/?format=pdf\&lang=pt. Acesso em: 06 out. 2021.

BRASIL. Constituição da República Federativa do Brasil, DF: Senado Federal: Centro Gráfico, 1988.

BUTLER, Judith. Problemas de gênero: feminismo e subversão da identidade. 19. ed. Rio de Janeiro: Civilização Brasileira, 2020.

CARRARA, Sergio et al. Política, Direitos, Violência e Homossexualidade. Pesquisa 9a Parada do Orgulho GLBT - São Paulo 2005. Coleção Documentos, v. 5. Rio de Janeiro: CEPESC, 2006. Disponível em: http://www.clam.org.br/uploads/arquivo/paradasp_2005.PDF. Acesso em: $8 \mathrm{dez} .2020$.

DINIS, Nilson Fernandes; PAMPLONA, Renata Silva. "Encontrando Bianca": discursos sobre o corpo-travesti. Pro-Posições, Campinas, v. 25, n. 2, p. 217-236, ago. 2014. Disponível em: http://www.scielo.br/scielo.php?script=sci_arttext\&pid=S0103-73072014000200012\&Ing=en\&nrm=iso. Acesso em: 5 nov. 2020.

INEP. Projeto de estudo sobre ações discriminatórias no âmbito escolar (...). São Paulo, 2009. Disponível em: http://portal.mec.gov. br/dmdocuments/relatoriofinal.pdf. Acesso em: 8 dez. 2020.

LAQUEUR, Thomas. Inventando o sexo: corpo e gênero dos gregos a Freud. Rio de Janeiro: Relume Dumará, 2001.

LOURO, Guacira Lopes. Gênero, sexualidade e educação. Uma perspectiva pós-estruturalista. Petrópolis, RJ: Vozes, 1997.

LOURO, Guacira Lopes. Um corpo estranho: ensaios sobre sexualidade e teoria queer. 3. ed. Belo Horizonte: Autência Editora, 2018.

MOLINA, Luana P. P. "Yo solo soy": Os processos de transições corporais de estudantes trans no Bachillerato Popular Trans Mocha Celis. Sex., Salud Soc. (RJ) Rio de Janeiro, n. 34, p. 108-125, abril 2020. Disponível em http://www.scielo.br/scielo.php?script=sci_arttext\&pid=S1984-64872020000100108\&Ing=en\&nrm=iso. Acesso em: 5 dez. 2020.

MOREIRA, Maria Ignez Costa et al. Mulheres, travestis e transexuais: interseções de gênero em documentos de políticas públicas. Fractal, Rev. Psicol. Rio de Janeiro, v. 30, n. 2, p. 234-242, ago. 2018. Disponível em: http://www.scielo.br/scielo.php?script=sci_arttext\&pid=S1984-02922018000200234\&lng=en\&nrm=iso. Acesso em: 5 dez. 2020.

OEA. AG/RES. 2435 sobre Derechos Humanos, Orientación Sexual e Identidad de Género. 2008. Disponível em: https://www.oas. org/dil/esp/ag-res_2435_xxxviii-o-08.pdf. Acesso em: 4 set. 2021.

OECD (2019), Society at a Glance 2019: OECD Social Indicators, OECD Publishing, Paris. Disponível em: https://doi.org/10.1787/ soc_glance-2019-en. Acessado em 14 de novembro de 2020.

PEDRA, Benevides Caio. Cidadania trans: o acesso à cidadania por travestis e transexuais no Brasil. 1. ed. Curitiba: Appris, 2020.

SALES, Adriana; SOUZA, Leonardo Lemos de; PERES, Wiliam Siqueira. Travestis brasileiras e escola: problematizações sobre processos temporais em gêneros, sexualidades e corporalidades nômades. Fractal, Rev. Psicol. Rio de Janeiro, v. 29, n. 1, p. 71-80, abril 2017. Disponível em: http://www.scielo.br/scielo.php?script=sci_arttext\&pid=S1984-02922017000100071\&lng=en\&nrm=iso. Acesso em: 5 nov. 2020.

SANTOS, Dayana Brunetto Carlin dos. A biopolítica educacional e o governo de corpos transexuais e travestis. Cad. Pesqui. São Paulo, v. 45, n. 157, p. 630-651, set. 2015. Disponível em: http://www.scielo.br/scielo.php?script=sci_arttext\&pid=S0100-15742015000300630\&Ing=en\&nrm=iso. Acesso em: 5 nov. 2020.

SILVA, Glauber Weder dos Santos et al. Situações de violência contra travestis e transexuais em um município do nordeste brasilei- 
ro. Rev. Gaúcha Enferm. Porto Alegre, v. 37, n. 2, e56407, 2016. Disponível em http://www.scielo.br/scielo.php?script=sci_arttext\&pid=S1983-14472016000200404\&Ing=en\&nrm=iso. Acesso em: 5 nov. 2020.

SIMPSON, Keila. Parte I - Movimento Social: relatos de vivências e lutas contra o preconceito e pelo direito à saúde: Transexualidade e Travestilidade. In: BRASIL. Ministério Da Saúde. Transexualidade e Travestilidade na Saúde. Brasília, DF, 2015, p. 9-15.

SOUSA, Patricia Juliana de; FERREIRA, Luiz Oscar Cardoso; SÁ, Janilson Barros de. Estudo descritivo da homofobia e vulnerabilidade ao HIV/Aids das travestis da Região Metropolitana do Recife, Brasil. Ciênc. saúde coletiva, Rio de Janeiro, v. 18, n. 8, p. 2239-2251, ago. 2013. Disponível em: http://www.scielo.br/scielo.php?script=sci_arttext\&pid=S1413-81232013000800008\&lng=en\&nrm=iso. Acesso em: 12 nov. 2020.

SOUZA, Martha Helena Teixeira de et al. Violência e sofrimento social no itinerário de travestis de Santa Maria, Rio Grande do Sul, Brasil. Cad. Saúde Pública, Rio de Janeiro, v. 31, n. 4, p. 767-776, abril 2015. Disponível em: http://www.scielo.br/scielo.php?script=sci_arttext\&pid=S0102-311X2015000400767\&Ing=en\&nrm=iso. Acesso em: 5 nov. 2020.

TORRES, Marco Antônio; PRADO, Marco Aurélio. Professoras transexuais e travestis no contexto escolar: entre estabelecidos e outsiders. Educ. Real. Porto Alegre, v. 39, n. 1, p. 201-220, mar. 2014. Disponível em: http://www.scielo.br/scielo.php?script=sci_arttext\&pid=S2175-62362014000100012\&lng=en\&nrm=iso. Acesso em: 5 nov. 2020.

TORRES, Marco Antônio; SARAIVA, Izabella Marina Martinho; GONZAGA, Rubens Modesto. Sexualidades no contexto escolar: violência ética e disputas por reconhecimento. Rev. Bras. Educ. Rio de Janeiro, v. 25, e250049, 2020. Disponível em: http://www. scielo.br/scielo.php?script=sci_arttext\&pid=S1413-24782020000100237\&lng=en\&nrm=iso. Acesso em: 12 nov. 2020.

UNHCHR. Nascidos livros e iguais: orientação sexual e identidade de gênero no regime internacional de direitos humanos. Nova York e Genebra, 2012, Brasília, 2013. Disponível em: www.ohchr.org/Documents/Publications/BornFreeAndEqualLowRes_Portuguese.pdf. Acesso em: 4 set. 2021.

VERGUEIRO, Viviane. Por inflexões decoloniais de corpos e identidades de gênero inconformes: uma análise autoetnográfica da cisgeneridade como normatividade. 2016. Tese (Doutorado) - Instituto de Humanidades, Artes e Ciências Professor Milton Santos, Universidade Federal da Bahia, Salvador, BA, Brasil. Disponível em: Acesso em: https://repositorio.ufba.br/ri/handle/ ri/19685. Acesso em: 24 de março de 2021.

VIGANO, S. M. M.; LAFFIN, M. H. L. F. Gênero e Sexualidade: concepções e discussões acerca da educação. Rev. Espaço do currículo (online), João Pessoa, v.12, n.1, p. 209-222, jan./abr. 2019. Disponível em: Portal de Periódicos da UFPB. Acesso em: 22 de jan de 2022.

YOGYAKARTA. Princípios sobre a Aplicação da Legislação Internacional de Direitos Humanos em relação à Orientação Sexual e identidade de Gênero. Yogyakarta, 2007. Disponível em: http://www.dhnet.org.br/direitos/sos/gays/principios_de_yogyakarta.pdf Acesso em: jan. 2022. 